BRIEF REPORTS

\title{
A SINISTER BIAS IN HIP SOCKET WEAR:
}

\section{BRIEF REPORT}

\author{
G. H. ISAAC, J. P. HODGKINSON, B. M. WROBLEWSKI
}

It has long been appreciated that wear rates for polyethylene against stainless steel, obtained from laboratory testing, are much lower than those obtained from clinical data. In addition, the rates of wear within a group of patients whose hips have been revised varies from 0.005 to $0.6 \mathrm{~mm} /$ year (Atkinson et al. 1985). These differences have been explained by various factors: patient characteristics, variation in polyethylene samples, inadequate testing techniques, roughness of femoral heads and creep.

In the hope of clarifying some of the discrepancies between wear results, a study was undertaken of 50 patients in whom Charnley low friction arthroplasties had been inserted bilaterally at the same operation. This

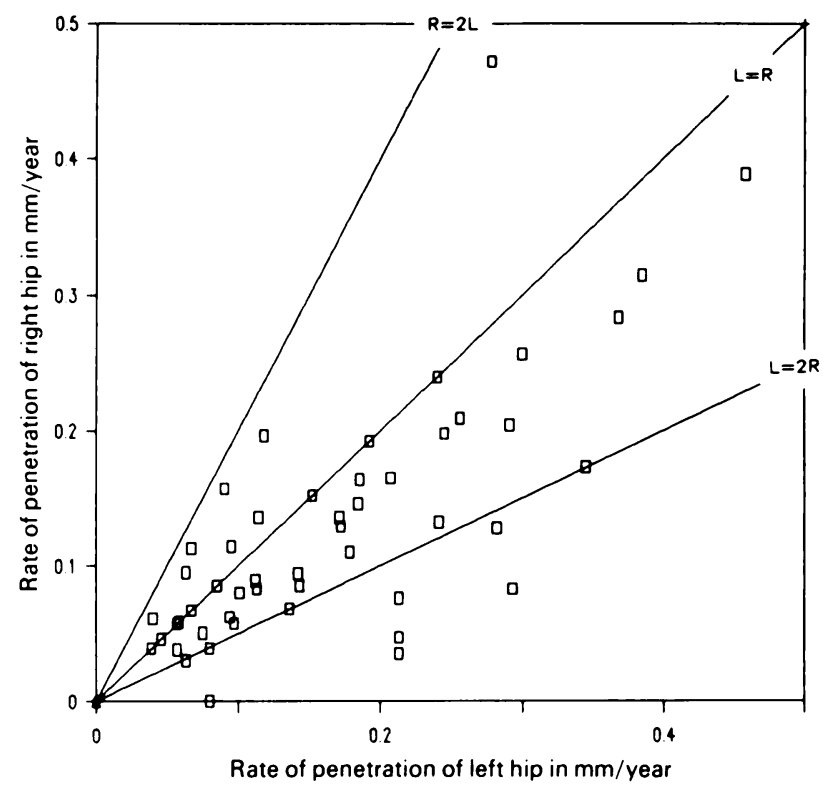

Fig. 1

allowed direct comparison of the rates of wear of the right and left hip in each patient. The socket penetration was measured directly from radiographs. Of the 50 patients, 30 were women. The average age at operation was 50.4 years (range 30.3 to 69.9 years) and the average pre-operative weight was $65.7 \mathrm{~kg}$ (range 34.1 to $92.3 \mathrm{~kg}$ ). The diagnosis was primary osteoarthritis in 37 , rheumatoid arthritis in five, old congenital dislocation in six; in two it was not established. The average follow-up was 9.1 years (range 5.1 to 15.5 years).

Results. The findings of the study are presented in Figure 1 which compares the penetration rate of the right and left hip of each patient, showing that in 33 patients wear was greater on the left (in nine it was over twice as great), while it was equal in nine and greater on the right in only eight. A paired-comparison Student's $t$-test may be used despite the non-normal distribution (Fig. 2); this gave a significance level of $p<0.001$ to the hypothesis that the penetration rates of opposite hips are not equal. The mean penetration rate of the left hip was $0.162 \mathrm{~mm} /$ year and that of the right hip was $0.126 \mathrm{~mm} /$ year. A distribution free test produces the same conclusion.

Discussion. This study eliminates the effects of patient characteristics since we compared the wear rates of both hips in the same patient. However, the results show a statistically significant higher rate of wear in the left sockets than in the right. It seems unlikely that this difference could be due to chance variation in the physical properties of the polyethylene socket, or to in vivo roughening (Isaac et al. 1987).

There is little in the surgical technique that could

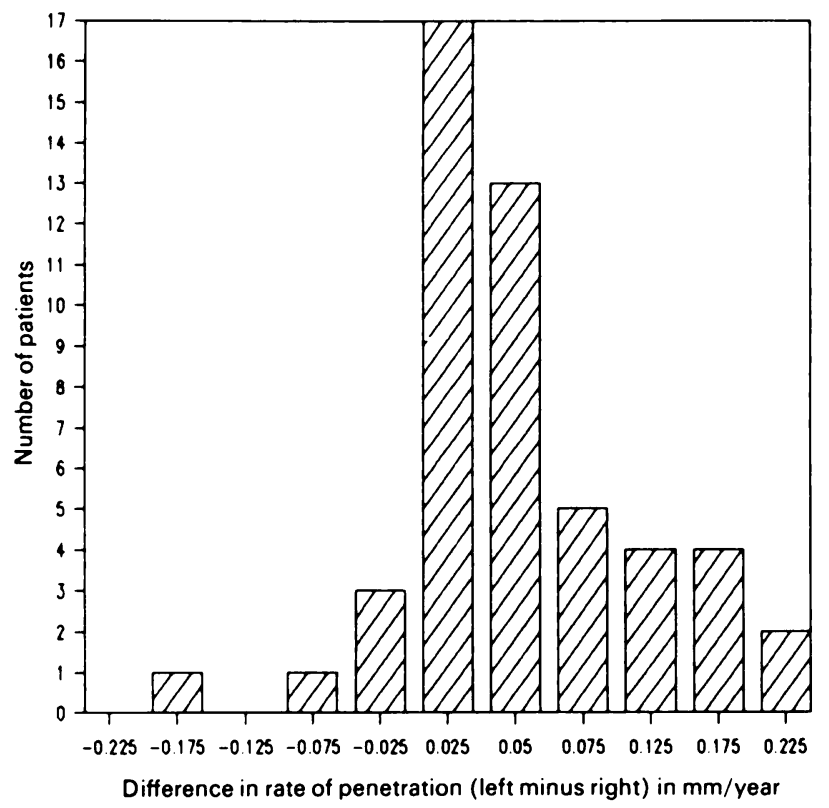

Fig. 2 
account for the difference, although all the surgeons performing the operations were right-handed. Two factors merit further examination: leg length discrepancy and the level of each patient's activity. The anatomical difference in leg length is easy enough to measure clinically or radiologically, but the "functional" discrepancy is less easy to measure and may well be of greater importance. The present methods of assessing

G. H. Isaac, PhD, Research Fellow

J. P. Hodgkinson, FRCS, Senior Orthopaedic Registrar

B. M. Wroblewski, FRCS, Consultant Orthopaedic Surgeon

Centre for Hip Surgery, Wrightington Hospital, Wigan, Lancashire WN6 9EP, England.

Correspondence to Dr G. H. Isaac.

(C) 1989 British Editorial Society of Bone and Joint Surgery 0301-620X/89/1R69\$2.00

J Bone Joint Surg [Br] 1989;71-B:143-4. patient activity are not very sensitive and need to be improved if we are to understand the results described in this paper.

No benefits in any form have been received or will be received from a commercial party related directly or indirectly to the subject of this article.

\section{REFERENCES}

Atkinson JR, Dowson D, Isaac JH, Wroblewski BM. Laboratory wear tests and clinical observations of the penetration of femoral heads into acetabular cups in total replacement hip joints: III. the measurement of internal volume changes in explanted Charnley sockets after 2-16 years in vivo and the determination of wear factors. Wear 1985;105:225-44.

Isaac GH, Atkinson JR, Dowson D, Kennedy PD, Smith MR. The causes of femoral head roughening in explanted Charnley hip prostheses. Engng Med 1987:16:167-73.

\title{
FAMILIAL SYNOVIAL CHONDROMATOSIS:
}

\section{BRIEF REPORT}

\author{
GERALD G. STEINBERG, SANJAY S. DESAI, RAJWANT MALHOTRA, ROGER HICKLER
}

In synovial chondromatosis, foci of metaplastic cartilage form in the synovial membrane of a joint. These foci may grow, become detached from the synovial membrane and enter the joint cavity as loose bodies. Calcification or ossification of the cartilage masses may occur (Jaffe 1958). As far as we know no cases of synovial chondromatosis with a familial pattern have been reported. We describe a family in which three men are affected.

Case reports. $\mathrm{RH}$, a 57-year-old white man, FH, his 63- year-old brother, and DG, their 36-year-old nephew, presented with remarkably similar histories of recurrent swelling and derangement of the right knee since young adulthood. When first seen each had a moderate effusion with multiple palpable mobile loose bodies. Both RH and DG had mild restriction of movement. Their radiographs also were similar. That of $\mathrm{RH}$ was typical, showing multiple radiopaque masses consistent with calcified or ossified loose bodies (Fig. 1); some degenerative changes also were seen.
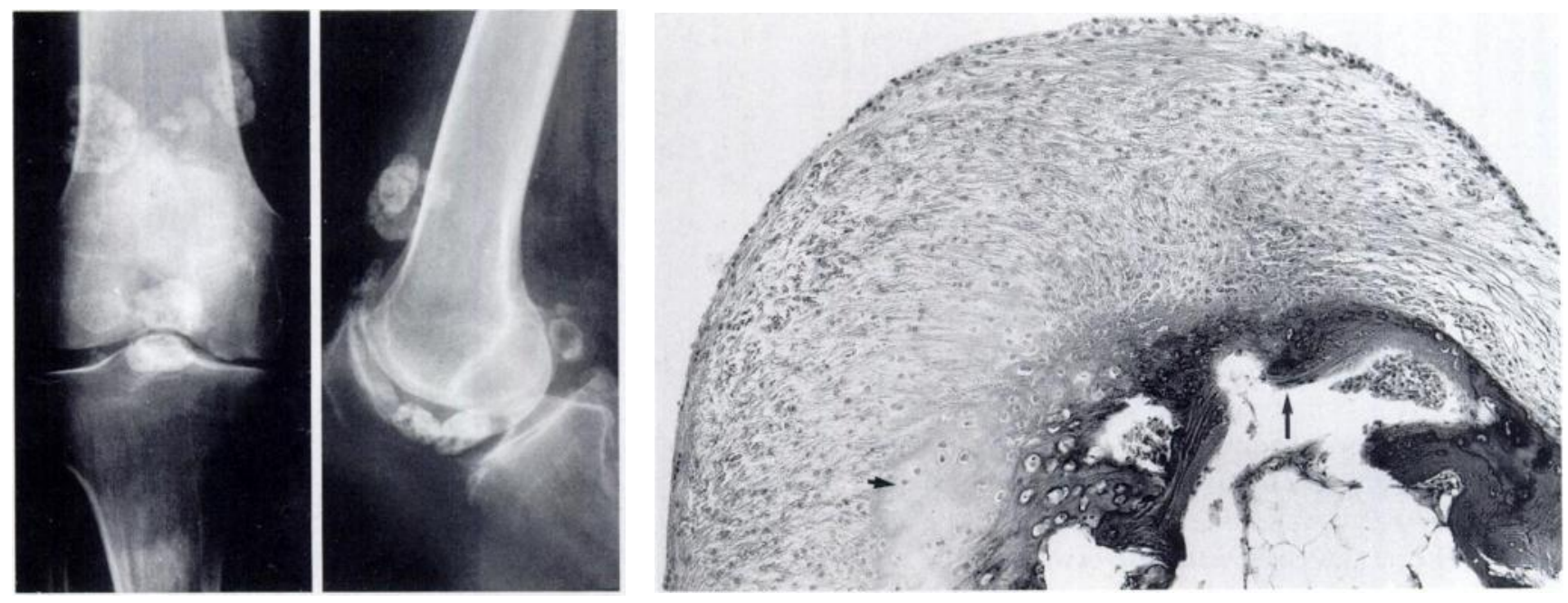